\title{
Saúde bucal de escolares no município de Piracicaba-SP
}

\author{
Fernanda R. de F. Santos (IC), Caroline Zeeberg (IC), Marília J. Batista (PQ), Maria da Luz de Sousa \\ (PQ).
}

\section{Resumo}

O objetivo desse estudo foi avaliar estratégias educativas e preventivas de saúde bucal em crianças 07 a 12 anos. A amostra consistiu em escolares de 07 a 12 anos de idade, do grupo teste (87 crianças) e controle (74 crianças). Os pais ou responsáveis pelas crianças responderam um questionário específico relativo aos hábitos familiares. Em seguida as crianças incluídas no trabalho foram submetidas ao exame clínico bucal para avaliação da experiência de cárie através do índice CPOD e ICDAS, condições gengivais e necessidades de tratamento. Com base nos dados coletados, os escolares foram classificados quanto ao grupo de risco para cárie. A partir dos resultados obtidos foi elaborado um programa preventivo educativo em saúde bucal voltado para as crianças do grupo teste de acordo com o grupo de risco apresentado.

Palavras Chave: cárie, escolares, programas preventivos.

\section{Introdução}

A cárie é uma das maiores doenças da cavidade oral, afeta a saúde do indivíduo, seu comportamento social e sua qualidade de vida. $\mathrm{Na}$ dentição decídua predispõe o individuo a apresentá-la na dentição permanente. É de extrema importância práticas efetivas preventivas que diminuam os fatores predisponentes ao desenvolvimento da doença nessa faixa etária.

\section{Resultados e Discussão}

Quanto à idade,o grupo teste tem em média 8,39 anos e o controle 7,57 anos. Quanto ao gênero, a maioria pertence ao sexo feminino em ambos os grupos, teste (59 meninas) e controle (68 meninas).

Ao exame do CPOS do grupo teste inicial foi de 1,98 e final de 1,60 e no grupo controle inicial de 2,67 e final de 2,49 . O ceos no grupo teste inicial foi de 2,68 e final de 2,17 e no grupo controle inicial de 0,18 e final de 0,18 .

Ao exame do biofilme dental, ocorreu melhora no índice de biofilme dental no grupo teste de uma média de 23,53 para 18,73. No grupo controle, de 23,93 para 22,01 superfícies com biofilme.

Ao exame do ICDAS II, houve diferença entre a média de manchas brancas sendo no grupo teste inicial de 0,81 e no final de 0,48, $\quad(p<0,01)$ apresentando resultado significante ao grupo. No grupo controle não houve diferença significante $(p$ $0,110)$.
Quanto a condição gengival das crianças antes e após o programa e observou-se que redução da condição de gengiva com alterações inflamatórias $(p<0,05)$ no grupo teste.

$\mathrm{Na}$ Tabela 1 estão apresentados os dados da distribuição das crianças de acordo com o risco à cárie, o que definiu quais as atividades preventivas que a criança participou.

\section{Conclusões}

O grupo teste apresentou redução dos índices de placa, condição gengival e também de manchas brancas. O programa se mostrou efetivo principalmente na questão da diminuição das manchas brancas quando comparado ao grupo teste.

\section{Agradecimentos}

Agradeço a FAPESP por ser a instituição que permitiu $O$ desenvolvimento da pesquisa. Agradeço a orientadora e co-orientadora por coordenarem o projeto e as escolas envolvidas.

1PEREIRA, Antonio Carlos., 2003. Cap.4 e 5.

${ }^{2}$ RIHZ, B.L.; SOUSA, M.L.R. DE; CYPRIANO, S.; ABDALLA, ${ }^{3}$ N.M.; GUIDINI, D.D.N.; AMGARTEN, C. 2004. Cad Saúde Pública, Rio de Janeiro, 23(3):593-600, mar, 2007.

4BRASIL. Ministério da Saúde. Projeto SB Brasil 2010:Resultados principais. Brasília: Ministério da Saúde. 2011.34p. 